African Journal of Biomedical Research, Vol. 10 (2007); 133 - 139

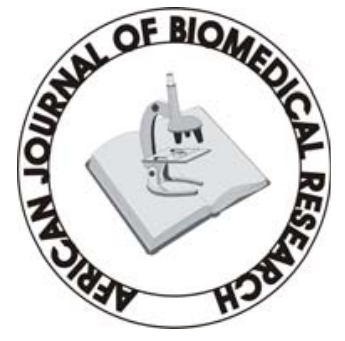

Full-text available at http://www.ajbrui.com http://www.bioline.br/md http://www.ajol.com

Received:

October 2007

Accepted (Revised):

February 2007

Published

May 2007
Full Length Research Article

\section{Evaluation of Plasma Lipids and Lipoproteins in Nigerians Suffering From Depressive Illness}

\author{
Onuegbu A.J*, Agbedana E.O**, Baiyewu O***, Olisekodiaka \\ M.J**, Ebesunun, M.O**, Adebayo K***, Ayelagbe O.G $* * * *$, \\ Adegoke, O.D.*. \\ Departments of *Biomedical Sciences and $* * * *$ Chemical Pathology, College of Health \\ Sciences, Osogbo, Ladoke Akintola University of Technology, Ogbomosho. \\ Department of **Chemical Pathology, College of Medical Science, University of Ibadan, \\ Ibadan. \\ Department of ***Psychiatry, University College Hospital, Ibadan.
}

\section{ABSTRACT}

There are conflicting reports on the role of plasma lipids in depressive illness. Very little is known about the lipid and lipoprotein status in Nigerian adults suffering from depression. One hundred subjects consisting of sixty (60) depressed patients with mean age $(40.3 \pm 12.3$ yrs) and forty (40) apparently healthy controls ( $40.1 \pm 10.1$ yrs) were selected for the study. All subjects were free from medication at least one month prior to the start of the experiment. The anthropometric indices were also determined. There was a significant increase in plasma triglyceride concentration in depressed subjects when compared to control values $(\mathrm{p}<0.01)$. However, the plasma total cholesterol, low density lipoprotein cholesterol (LDL-C), high density lipoprotein cholesterol (HDL-C) and body mass index (BMI) did not significantly differ from control values. The mean plasma triglyceride was significantly increased in female patients in comparison to corresponding female controls. Plasma lipid and lipoprotein levels did not demonstrate any definite pattern with increasing level of depression in patients. In conclusion, plasma lipid levels could play a significant role in depressive illness in Nigerians

(Afr. J. Biomed. Res. 10: 133 - 138

Keywords: Depression, triglyceride, cholesterol, lipoproteins.

*Address for Correspondence: Onuegbu, A. J., Department of Biomedical Sciences, College of Health Sciences, Osogbo, Ladoke Akintola University of Technology, Ogbomosho

\section{INTRODUCTION}

Depression is a growing health problem and one of

Abstracted by:

African Index Medicus (WHO), CAB Abstracts, Index Copernicus, Global Health Abstracts, Asian Science Index, Index Veterinarius, Bioline International , African Journals online 
the least understood diseases. It is differentiated from normal mood changes by the extent of its severity, the symptoms and the duration of the disorder (Murray and Lopez, 1996). The exact cause is not known (Baldwin, 2000). Untreated depression may lead to suicide, which is one of the leading causes of death in the western parts of the world (Klebba, 1979).

Among Africans, earlier studies suggested that depression was rare (Carothers, 1947) but later studies have revealed an increasing prevalence of this condition in many African communities (Leighton et al, 1963, Wintrob, 1967). Evidence suggesting any possible relationship between plasma lipids and mental illness has been conflicting. Boston et al(1996) reported that significant changes in serum lipids might be linked with mental health. Some studies have found that cholesterol is important for the uptake of serotonin, a neurotransmitter which when present at low levels in circulation, is associated with depression (Engelberg, 1992, Maes et al, 1995). In a large Swedish population, Suarez et al (1999) noted that a low serum cholesterol level was associated with a higher prevalence of depression in middle-aged women. Also several studies have reported low total plasma cholesterol concentrations in depression (Glueck et al, 1994, Chen et al, 2000) while others did not show any relationship between circulating levels of cholesterol and incidence of depression (McCallom et al, 1994). However, in some earlier studies (van Doornen and van Blockland, 1987, Shizuka and Yambe, 2001) significantly elevated plasma lipid concentrations were associated with persistent depressive feelings.

Lipids and some elemental micronutrients constitute major parts of the human brain. Therefore, it is speculated that factors affecting cerebral lipid could have profound effects on normal brain function (McLoughlin and Clarke, 1989).

Depressive illness is a major cause of morbidity and mortality especially in the elderly (Baldwin, 2000). Age, gender, apolipoprotein E phenotypes, condition of fraility and inflammation states are important factors that can induce significant modification in lipid profile in the elderly (Etukudo et al, 1999). Also, hypocholesterolaemia is associated with diseases like malnutrition and some chronic diseases which are common in the elderly in different populations (Siemianowiwicz et al, 2000, Zuliani et al, 2001). The presence of all such confounding factors had previously made it difficult to confirm a close link between low serum cholesterol and depression in the elderly populations. Recent interest in biological basis of neurological disorders has attracted much interest worldwide, but there is scanty information on systematic lipid studies in Nigerian Africans. The present study was designed to evaluate the lipid and lipoprotein profiles in adult Nigerians suffering from varying degrees of depression, to assess the confounding effects of gender and the tendency to commit suicide on the possible association between circulating plasma lipid and depression in the Nigerian African.

\section{MATERIALS AND METHODS}

Subjects: One hundred (100) subjects were selected for this study after ethical committee approval by the UI/UCH joint ethical committee. The study group was made up of sixty (60) depressed subjects (38 females, 22 males) mean age $(40.3 \pm 12.3)$ yrs and forty normal controls (21 females, 19 males) mean age $(40.1 \pm 10.1)$ yrs. All the subjects were free from medication for at least one month prior to the start of the experiment. All were normotensive, nondiabetic, without renal or liver dysfunction and with a body mass index (BMI) of less than $30 \mathrm{~kg} / \mathrm{m}^{2}$. None of the patients had received lithium therapy. Subjects who frequently took alcohol or smoked or those on a special diet were excluded from the study.

Diagnosis of depression was made using the Diagnostic and Statistical Manual of Mental Disorders (DSM-IV) criteria at the Psychiatry Department of the University College Hospital Ibadan by the attendant Consultant Psychiatrist. Other scales used in the study are Hamilton Depression Rating Scale (HDRS) which allows a clinician to rate the severity of depressive symptoms and Center for Epidemiological Studies on Depression Scale (CESD), a self-report questionnaire used mainly in primary care. Normal controls were required to score below 16 on application of CESD (Zich and Attkisson, 1990) and none of them reported any past history of past 
history or family history of psychiatric illness. Patients were subsequently classified into clinical subgroups as mild (HDRS 16-25), moderate (HDRS 26-34) and severe depression (HDRS > 34).

Blood Samples: Ten (10) ml of blood was obtained from each patient and control after an overnight fast. Aliquot of samples were drawn into sodium EDTA for lipid analysis and in heparin containers for determination of other biochemical parameters. Blood samples were centrifuged and plasma separated and stored below $-25^{\circ} \mathrm{C}$ until analysis was carried out.

Physical Parameters: Weights and heights were measured in kilogram and meters respectively. The $\mathrm{BMI}$ was then calculated as $\mathrm{BMI}=\mathrm{kg} / \mathrm{m}^{2}$.

Methods: Enzymatic colorimetric methods were employed for the estimation of plasma total cholesterol (Allain et al, 1974) and triglyceride (Buccolo and David, 1973) HDL-cholesterol was also determined using enzymatic colorimetric methods after separation from other lipoproteins using a mixture of phosphotungstic acid and magnesium chloride. LDL-cholesterol was calculated using the formular of Friedwald et al (1972) while activities of liver enzymes (aspartate and alanine transferases) and plasma albumin levels were determined using the methods of Bergmeyer et al (1986) and Doumas and Watson (1971) respectively.

Statistical Analysis: Results were expressed as mean \pm standard deviation. Comparison of means was made using the student-t- test and $\mathrm{p}<0.05$ regarded as significant. Group comparisons were carried out using one-way analysis of variance (ANOVA). Pearson correlation coefficient (r) was used to determine the relationship between variables.

\section{RESULTS}

The slight increase in the mean values of total cholesterol (TC) and low density lipoprotein cholesterol (LDL-C) observed in all depressed patients were not statistically significant $(p>0.05)$ when compared with the corresponding values in the control subjects (Table 2). Similarly, the reduction in mean high-density lipoprotein cholesterol (HDL) in depression was not statistically significant. On the other hand, the increase in mean plasma Triglyceride concentration in depressed patients when compared with the concentration in the control group was significant $(\mathrm{p}<0.01)$.

TABLE 1: Age, Body Mass Index (BMI), Weight and Height in Patients and controls.

\begin{tabular}{lcccc}
\hline Physical Parameters & Depression (N=60) & Control (N=40) & t-value & P \\
\hline AGE $(\mathrm{Yrs})$ & $40.3 \pm 12.3$ & $40.1 \pm 10.1$ & 0.1069 & N.S \\
\hline BMI $\left(\mathrm{Kg} / \mathrm{m}^{2}\right)$ & $21.9 \pm 3.4$ & $21.6 \pm 2.7$ & 0.353 & N.S \\
\hline Weight $(\mathrm{Kg})$ & $61.8 \pm 13.2$ & $57.2 \pm 16.5$ & 1.476 & N.S \\
\hline Height $(\mathrm{m})$ & $\mathrm{I} .68 \pm 0.2$ & $1.63 \pm 0.5$ & 0.601 & N.S \\
\hline
\end{tabular}

$N=$ number of subjects; N.S = Not significant

TABLE 2: Plasma Cholesterol, Triglyceride, HDL And LDL Levels in Patients and Controls

\begin{tabular}{|l|c|c|c|c|}
\hline Parameters & Depression (N=60) & Control (N=40) & t- value & P \\
\hline Total cholesterol (mg/dl) & $172 \pm 33$ & $171 \pm 35$ & 0.114 & N.S \\
\hline Triglyceride (mg/dl) & $87 \pm 26$ & $70 \pm 19$ & 3.561 & P $<0.01$ \\
\hline HDL-c (mg/dl) & $48 \pm 16$ & $53 \pm 12$ & 1.8998 & N.S \\
\hline LDL-c (mg/dl) & $107 \pm 29$ & $101 \pm 38$ & 0.788 & N.S \\
\hline AST (I U/L) & $23 \pm 11.6$ & $25 \pm 8.8$ & 1.196 & N.S \\
\hline ALT (IU/L) & $15 \pm 12.1$ & $16 \pm 6.3$ & 0.536 & N.S \\
\hline Albumin (g/dl) & $4.2 \pm 0.50$ & $4.3 \pm 0.4$ & 0.939 & N.S \\
\hline
\end{tabular}

$N=$ Number of Subjects; $H D L c=$ High density lipoprotein cholesterol; $L D L c=$ Low density lipoprotein cholesterol; N.S = Non-significant 
TABLE 3: Plasma Lipids, Lipoprotein Cholesterol Concentrations in Male and Female Patients

\begin{tabular}{|c|c|c|c|c|}
\hline Parameters & & Depression & Control & D Vs C \\
\hline \multirow{2}{*}{$\begin{array}{l}\text { Cholesterol } \\
\text { (mg/dl) }\end{array}$} & Female & $171 \pm 31(\mathrm{n}=38)$ & F $180 \pm 31(n=21)$ & \multirow{2}{*}{$\begin{array}{l}\mathrm{M} \text { vs } \mathrm{M}^{\mathrm{NS}} \\
\mathrm{F} \text { vs } \mathrm{F}^{\mathrm{NS}}\end{array}$} \\
\hline & Male & $174 \pm 38^{\mathrm{NS}}(\mathrm{n}=22)$ & M $162 \pm 37(n=19)$ & \\
\hline \multirow{2}{*}{$\begin{array}{l}\text { Triglyceride } \\
(\mathrm{mg} / \mathrm{dl})\end{array}$} & Female & $84 \pm 22(n=38)$ & $\mathrm{F} 62 \pm 11(\mathrm{n}=21)$ & \multirow{2}{*}{$\begin{array}{l}\mathrm{M} \text { vs } \mathrm{M}^{\mathrm{NS}} \\
\mathrm{F} \text { vs } \mathrm{F}, \mathrm{p}<0.01\end{array}$} \\
\hline & Male & $91 \pm 32^{\mathrm{NS}}(\mathrm{n}=22)$ & M $78 \pm 23(n=19)$ & \\
\hline \multirow{2}{*}{$\begin{array}{l}\text { HDL-c } \\
\text { (mg/dl) }\end{array}$} & Female & $50 \pm 15(n=38)$ & F $52 \pm 14(n=21)$ & \multirow{2}{*}{$\begin{array}{l}\text { M vs } M, p<0.01 \\
F_{\text {vs F }}{ }^{N S}\end{array}$} \\
\hline & Male & $44 \pm 12^{\mathrm{NS}}(\mathrm{n}=22)$ & M $54+9(n=19)$ & \\
\hline \multirow{2}{*}{$\begin{array}{l}\text { LDL-c } \\
(\mathrm{mg} / \mathrm{dl})\end{array}$} & Female & $105 \pm 28(n=38)$ & F $110 \pm 40(n=21)$ & \multirow{2}{*}{$\begin{array}{l}\mathrm{M} \text { vs } \mathrm{M}^{\mathrm{NS}} \\
\mathrm{F} \text { vs } \mathrm{F}^{\mathrm{NS}}\end{array}$} \\
\hline & Male & $111 \pm 31^{\mathrm{NS}}(\mathrm{n}=22)$ & M $92 \pm 33(n=19)$ & \\
\hline
\end{tabular}

$n=$ number of subjects; $D$ Vs $C=$ Depression Vs Control; $H D L-c=$ High-density lipoprotein cholesterol $N S=$ Non-significant; $L D L-c=$ Low-density lipoprotein cholesterol; $p>0.05=N S ; M=$ Male; $F=$ Female

Table 4: Plasma Lipids, Lipoprotein Cholesterol Concentrations and LDL-C/HDL-C Ratio in Mild, Moderate and Severe Depression (Mean \pm SD)

\begin{tabular}{llllll}
\hline Parameters & $\begin{array}{l}\text { Mild } \\
\text { M1 (n=25) }\end{array}$ & $\begin{array}{l}\text { Moderate } \\
\text { M2 (n=25) }\end{array}$ & $\begin{array}{l}\text { Severe } \\
\text { M3 (n=10) }\end{array}$ & F & P \\
\hline Total Cholesterol (mg/dl) & $172 \pm 38$ & $169 \pm 29$ & $180 \pm 36$ & .422 & NS \\
\hline Triglyceride (mg/dl) & $87 \pm 27$ & $86 \pm 23$ & $89 \pm 31$ & .033 & NS \\
\hline LDL-c (mg/dl) & $108 \pm 28$ & $102 \pm 25$ & $115 \pm 42$ & .648 & NS \\
\hline HDL-c (mg/dl) & $50 \pm 17$ & $49 \pm 14$ & $48 \pm 21$ & .061 & NS \\
\hline LDLc/HDLc & $2.4 \pm 0.9$ & $2.2 \pm .8$ & $3.1 \pm 2.2$ & 1.9 & NS \\
\hline
\end{tabular}

$n=$ number of subjects; LDL-c=low-density lipoprotein cholesterol; HDL-c=High-density lipoprotein cholesterol

TABLE 5: Correlation Coefficients for Lipids, Lipoproteins and Depression Rating Scores in Depression

\begin{tabular}{cccccc}
\hline & TC & TG & HDL-C & LDL-C & HDRS \\
\hline TC & 1.00 & .153 & $.428^{\mathrm{b}}$ & $.890^{\mathrm{b}}$ & -.253 \\
\hline TG & .153 & 1.00 & -.204 & .112 & -.302 \\
\hline HDL-C & $.428^{\mathrm{b}}$ & -.204 & 1.00 & -.005 & -.061 \\
\hline LDL-C & $.890^{\mathrm{b}}$ & .112 & -.005 & 1.00 & -.182 \\
\hline HDRS & -.253 & -.302 & -.061 & -.182 & 1.00 \\
\hline
\end{tabular}

$\mathrm{a}=\mathrm{P}<0.05 ; \mathrm{b}=\mathrm{p}<0.01$

When the subjects were classified according to gender, (Table 3) compared with the corresponding values in male control subjects, there were no significant differences between the plasma total cholesterol, triglyceride and LDL-cholesterol in male depressed patients. On the other hand, only the mean plasma HDL- cholesterol level was significantly reduced in male patients when compared with the corresponding value in the male control subjects $(\mathrm{p}<0.01)$. In female depressed patients, the mean plasma total cholesterol, HDL- cholesterol and LDL-cholesterol levels were not statistically different from the corresponding mean values in the female control group. However, the mean concentration of plasma triglyceride in female depressed patients was significantly increased when compared with the concentrations in the female control group $(\mathrm{P}<0.01)$. As shown in table 4 , there were no significant differences in the plasma levels of total cholesterol, triglyceride, HDL-cholesterol and LDL-cholesterol between mild, moderate and severe depression. Similarly, plasma lipid and 
lipoprotein concentrations did not correlate with Hamilton Depression scores (HDRS) (Table 5)

\section{DISCUSSION}

The results of this study suggest that plasma total cholesterol was not associated with depression. Similarly, the changes in mean LDL-C and HDL-C concentrations were not significantly altered when compared to the respective values in the control group. These results in middle aged Nigerians of varying socio-economic classes agree with those of other studies (McCallom et al, 1994) but they are at variance with others who showed that the mean total cholesterol was either reduced (Chen et al, 2000) or elevated (Shizuka and Yambe, 2001) in depression. Mechanisms of action adduced by these workers were the speculated direct relationship between low cholesterol levels and poor serotonin uptake and lipid-induced increased viscosity leading to low cerebral perfusion respectively.

Inconsistencies among these various reports appear to suggest that the link between plasma total cholesterol and occurrence of depression is less straightforward than it might seem, probably, due to factors like age, other clinical conditions, nutritional factors or other life style factors that modulate plasma lipids. For instance, the significant inverse relationship between cholesterol and depression in a previous study were limited to elderly persons and some of the studies only made use of self-reporting questionnaires. Thus, it could not be ascertained what proportion of reported depression was clinically significant.

The most striking change in lipid profile in this study is the significant increase in plasma triglyceride in depression, irrespective of the severity of disease, mood (suicide tendency or not) or level of plasma total cholesterol. It was also noted that the change was more pronounced in female patients when compared with their male counterparts. The possible role of triglyceride metabolism in the aetiology of depression is largely unknown but Fowkes et al (Fowkes et al, 1992) in an earlier study indicated a positive relationship between serum circulating triglyceride concentration and personality trait in depression. Similarly, a previous study (Rogers et al, 1989) had reported that hypertriglyceridemia is associated with peripheral neuropathy and dementia especially in young subjects and the clinical conditions were reversed when a reduction in the grossly elevated lipids was achieved by drug or dietary therapy. It has been speculated that elevated lipids could enhance atherogenesis of the extracranial and intracranial arteries causing an increase in blood viscosity, which in turn decrease cerebral perfusion and impair cognitive performance (Fowkes et al, 1992). However, the finding in the present study is at variance with some others who could not confirm any association between high triglyceride values and depression or psychological symptoms.

Engelberg (1992) and Glueck et al (1994) had shown that low serum cholesterol concentration is associated with suicide. However, plasma lipid profiles in the subgroup of patients that had suicidal tendency or made an attempt to commit suicide in this study did not reveal an striking changes in lipid concentration when compared with the corresponding levels in other depressed subjects who had no tendency for suicide. The lack of statistically significant differences between the two groups included in the present study may be due to the small number of patients with suicidal tendency, a finding consistent with the suggestion (Asuni, 1962) that suicides appear to be uncommon in Nigerians. It was important to determine the liver function status in all the subjects studied, since neurological complications in liver diseases may often manifest in the form of intermittent confusion and abnormal behavior including tremor of the hands (Walton, 1984) The mean plasma albumin, a sensitive index of protein energy malnutrition as well as a measure of the synthetic ability of the liver and the activities of the aminotransferases were within normal range in the patients suffering from mild, moderate or severe depression.

In conclusion, this study suggests that altered triglyceride levels could contribute to depressive illness probably via increased blood viscosity leading to lowered cerebral perfusion.

\section{REFERENCES}

Allain, C. C., Poon, L. S., Chan, C. S. G. (1974). Enzymatic determination of total serum cholesterol. Clin. 
Chem., 20: 470-475.

Asuni, T. (1962). Suicide in Western Nigeria. Brit. Med. J., 2: 1091-1097

Baldwin R.C. (2000). Poor prognosis of depression in elderly people: causes and action. Ann. Med., 32: 252256.

Baldwin, R. C. (2000). Poor prognosis of depression in elderly people: causes and actions. Ann. Med., 32: 253256.

Bergmeyer, H. U., Horder, M, Rej, R. (1986). Approved recommendation (1985). Based on IFCC methods for the measurement of catalytic concentration of enzymes. J. Clin. Chem. Clin. Biochem., 24: 481-489.

Boston, P. F., Dursun, S. M., Reverley, M. A. (1996) Cholesterol and mental disorder. Br. J. Psychiat., 169: 682-689.

Buccolo, G., David, H. (1973). Quantitative determination of serum triglycerides by the use of enzymes. Clin. Chem., 19: 476-482.

Carothers, J. C. (1947). A study of mental derangement in Africans and an attempt to explain its peculiarities more especially in relation to the African attitude in life. J. Mental Sci., 93: 548-597.

Chen, C. C., Lu, F. H., Wu, J. S., Chang, C. J. (2001) Correlation between serum lipid concentrations and psychological distress. Psych. Res., 102: 153-162.

Doumas, B., Watson, W. (1971). The determination of serum albumin using bromocresol green. Clin. Chimica. Acta., 31: 87.

Engelberg, H. (1992). Low serum cholesterol and suicide. Lancet, 339: 727-729.

Etukudo, M. H., Agbedana, E. O., Akiyinka, O. O., Osifo, B. O. (1999). Plasma electrolytes, total cholesterol, liver enzymes and selected antioxidant status in protein energy malnutrition. Afr. J. Med. Med. Sci., 28 (1-2): 8185.

Fowkes, F. G., Leng, G. C., Donnan, P. T., Deary, I. J., Riemersma, R. A., Housely, E. (1992). Serum cholesterol, triglyceride and aggression in the general population. Lancet, 340 (8826): 995-998.

Friedwald, W. T., Levy, R. J., Fredrickson, D. S. (1972). Estimation of the concentration of low-density lipoprotein cholesterol in plasma without use of the preparative ultracentrifuge. Clin. Chem., 18: 499-509.

Glueck, C. J., Tieger, M., Kunkel, R., Hamer, T., Tracy, T., Spiecs, J. (1994). Hypocholesterolaemia and affective disorders. Am. J. Med. Sc.,, 308: 218-225.

Klebba, R. (1979). Comparisons of trends for suicide and homicide in the US 1900-1976. In: Violence and the violent individual. Hays, J. R., Roberts, T. K., Solway, K. S.(ed) SP Medical and Scientific books, New York. Pp. 127-148.

Leighton, A.H., Lambo, T. A., Hughes, C. C.,
Leighton, D. C., Murphy, J. M., Mackin, D. B.( 1947). Psychiatric disorders amongst the Yoruba. Cornell University press, New York. 1963; Pp 65-86.

Maes, M., Meltzer, H. Y. M. (1995). The serotonin hypothesis of major depression. In: Psychopharmacology the fourth generation of progress. Bloom, F., Kupher, D. (eds). Raven Press, New York. pp 933-941.

McCallom, J., Simons, I., Simons, J., Friedlander, Y. (1994). Lower serum cholesterol is not associated with depression in the elderly. Data from an Australian community study. Aust. NZ. J. Med., 24: 561-564.

Mcloughlin, I. J., Clarke, P. (1989). Lipid lowering drug. Br. J. Psychiat., 154: 275-276.

Murray, C.J.L., Lopez, A.D. (1996). Global burden of disease: a comprehensive assessment of mortality and disability from diseases, injuries and risk factors in 1990 and projected to 2020. Boston, MA: Harvard University Press, Pp 10-13.

Rogers. R. L., Meyer, J.S., McClintic, K., Mortel, K. F. (1989). Reducing hypertriglyceridemia in elderly patients with cerebrovascular disease stabilizes or improves cognition and cerebral perfusion. J. Vasc. Dis., 260-269. Shizuka, K., Yambe, T. (2001). Relationship between depression and lipid metabolism in the elderly with hypertension. Nippon Ronen Igakka zasshi., 38: 785-790. Siemianowiwicz, K., Gminski, J., Stajszczyk, M., Wojakowski, W., Goss, M., Machalski, M., Telega, A., Brulinski, K., Magiera-Molendowska, H. (2000) Serum cholesterol and triglyceride levels in patients with lung cancer. Int. J. Mol. Med., 5: 201-205.

Suarez, E. C. (1999). Relations of trait depression and anxiety to low lipid and lipoprotein concentrations in healthy young adult women. Psychosom. Med., 61: 273279.

Van Doornen, L. J. P., Van Blockland, R. (1987). Serum cholesterol: Sex specific psychological correlates during rest and stress. J. Psychosom., 31: 239-249.

Walton, J. (1984). Essentials of neurology. $5^{\text {th }} \mathrm{Ed}$. London. ELBS/ Low priced edition. p35-64.

Wintrob, P.A. (1967). Study of disillusionment depressive reactions of Liberian students returning from advanced training abroad. Am. J. Psychiat., 8: 811-824.

Zich, M. M., Attkisson, C. C. (1990). Screening for depression in primary care clinics. The CES-D and the BDI. Int. J. Psychiatry Med., 31 (3): 255-264.

Zuliani, G., Ble, A., Zanca, R., Munari, M. R., Zurlo, A., Vavalle, C., Atti, A. R., Fellin, R. (2001). Lipoprotein profile in older patients with vascular dementia and alzhemiars disease. BMC Geriatrics, 1(5): 1471-147 